\title{
AUGMENTED CITIZEN SCIENCE FOR ENVIRONMENTAL MONITORING AND EDUCATION
}

\author{
B. Albers ${ }^{a}$, N. de Lange ${ }^{a}, S . X u^{a}$ \\ ${ }^{a}$ Institute of Computer Science (IFI), University of Osnabrück, Wachsbleiche 27, 49090 Osnabrück, Germany \\ \{bastian.albers, ndelange, shaojuan.xu\}@uni-osnabrueck.de
}

Commission V, WG V/4

KEY WORDS: Augmented Reality, Citizen Science, Crowdsourcing, Environmental Monitoring, Environmental Education

\begin{abstract}
:
Environmental monitoring and ecological studies detect and visualize changes of the environment over time. Some agencies are committed to document the development of conservation and status of geotopes and geosites, which is time-consuming and costintensive. Citizen science and crowd sourcing are modern approaches to collect data and at the same time to raise user awareness for environmental changes.

Citizen scientists can take photographs of point of interests (POI) with smartphones and the PAN App, which is presented in this article. The user is navigated to a specific point and is then guided with an augmented reality approach to take a photo in a specific direction. The collected photographs are processed to time-lapse videos to visualize environmental changes. Users and experts in environmental agencies can use this data for long-term documentation.
\end{abstract}

\section{INTRODUCTION}

Taking photographs to document and to monitor the environment or specific environmental phenomena like landslides, changes of abrasion coasts or regular flooding of marshes or floodplains at various times over long periods is an important task for many environmental authorities and agencies. Volatile Situations, for example geotopes or geosites (Ielenicz, 2009) endangered by erosion, are captured and preserved for following generations through this. Data surveys or especially video documentations are cost and time consuming for agencies or scientists with limited resources and are therefore not always feasible.

Conservationists and professionals or scientists from environmental, geo and earth sciences often work in a very specific but sometimes in a very large study area. For scientific, environmentally relevant and typical landscape ecosystem issues a variety of diverse data has to be collected, processed and analysed. We propose a modern and intuitive augmented reality app for citizen scientists and use the wide distribution of smartphones equipped with many sensors to navigate people and to collect photographs of given locations of interest. One advantage over other citizen science projects is, that the user needs no expert knowledge of the given locations, the app helps the user take accurate photos of the desired area. Additional information like texts and pictures is used for environmental education and helps the user to understand the on-going environmental processes on-site.

\section{RELATED WORK}

In order to cope with this problem, modern approaches like citizen science or crowdsourcing can be used (Goodchild, 2007; Silvertown, 2009). Together with mobile technologies interested parties can become part of a community to support scientists and to help monitor their environment.
West et al. (2013) have shown a similar approach utilizing a rephotography approach with smartphones. By overlaying a reference outline over the current camera view the user is able to take a photo of the same object from the same point of view. The advantage of our approach is an easier navigation to the location and an augmented guiding approach that automatically triggers a photograph. Additionally, the on-board smartphone sensors are used to validate the correct orientation and location to exclude false positives.

Hadjiprocopis et al. (2014) show possible use cases for historical photography time series in an urban context. They reconstruct cultural heritage models in 3D and over time by using crowd sourced imagery from open access repositories. In times of climate changed it is of upmost interest to preserve our current environment but also to show younger generations how our surrounding nature changes over time. Data collected with this app by non-specialist citizens can therefore help to understand the current and the past natural processes.

As other works show (Kamarainen et al., 2013), Augmented Reality in combination with smartphones can help to support education, in this case environmental education. The special combination of taking photographs with smartphones to appeal to younger audiences is an additional value for nature agencies. By using modern technologies like crowdsourcing these agencies can monitor their parks and advertise naturecompatible tourism (West et al., 2013).

\section{PROPOSED APPROACH}

The project combines the idea of crowdsourcing and the wide distribution and acceptance of mobile apps to create a tool for environmental documentation and education. To reach a high number of participants the app is available for the operating systems iOS and Android. With this app, a user is navigated to a location of interest and guided to a virtual target. With the help 
of Augmented Reality technology (see chapter 4.2) the user aims the camera at the virtual target and an automatic photo is triggered when the target and camera view are aligned. An overview of the workflow is shown in Figure 1.

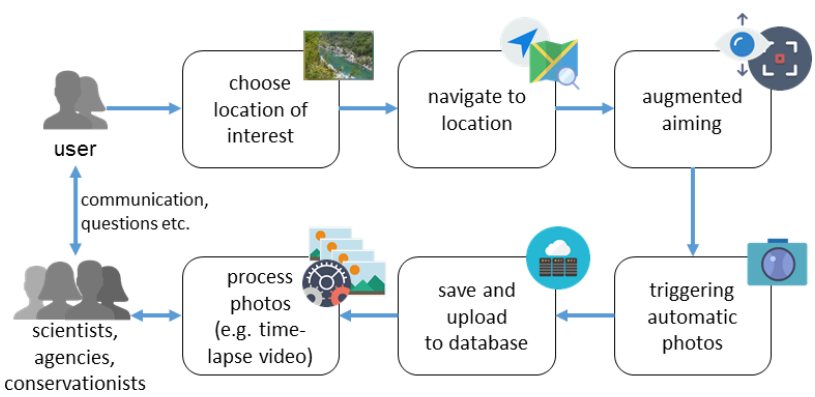

Figure 1. Workflow of the PAN project.

\section{METHODOLOGY}

The system architecture is based on a simple set-up consisting of a server connected to the web and the app as a mobile client. In the following chapters an overview of the used technology and software is given.

\subsection{Server and database}

The Server holds a MongoDB database which stores the geotope locations and additional information like graphics and descriptions. In order to accelerate the development, the open source Parse SDK is used as the backend. Only small adjustments are needed to communicate between a Parse server and the clients or to send photos from the app to the database.

\subsection{Augmented Reality and Augmented Guiding}

Augmented Reality (AR) tries to render virtual objects correctly positioned in the real world relative to the point of view of the users camera view in real time (Veas et al., 2013). A crucial factor for the quality and therefore the usability of the photos by experts is that the geotopes or geosites are captured over long time periods at the same location from the perspective as identical as possible. Our suggested solution is to use a geobased AR approach to guide the user to a pre-defined location and perspective.

A simple map view is used to show the approximate location of the point of interest until the user is in close proximity of the target location. The map shows the users current GPS location, the target and a compass arrow indicating the direction and distance the user has to go (see Figure 2). A standard turn-byturn navigation is not expedient in this case as many geotopes are far away from paved streets or paths. As soon as the user reaches the proximity of the target, the smartphone compass (magnetometer) has to be calibrated for the augmented reality view because the sensor data tend to drift and change between measurements and over time. This leads to moving virtual objects in the AR view and distracts and confuses the user. To calibrate the sensor, 200 measurements are taken at the target location to minimize statistical errors. These are then averaged and fixed.

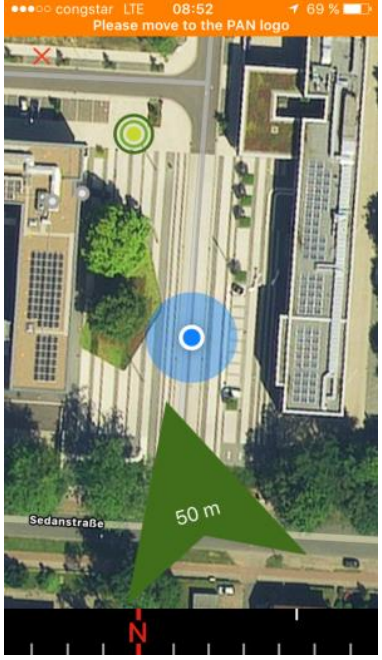

(a)

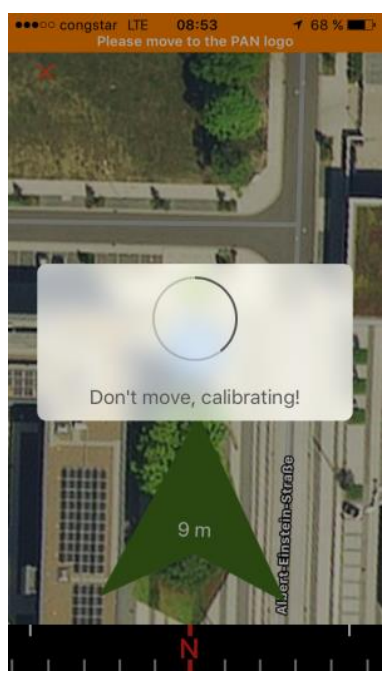

(b)
Figure 2. Simple navigation to a POI (a) and subsequent compass calibration (b).

When the compass is calibrated the map view switches to an AR view consisting of a photo location, target and compass (see Figure 3). In this AR view the user has to take the correct position and aim at the target object. If the correct perspective of the camera view is reached an automatic photo is triggered. After the photo is confirmed by the user it is uploaded to the server for further processing and evaluation.

(a)

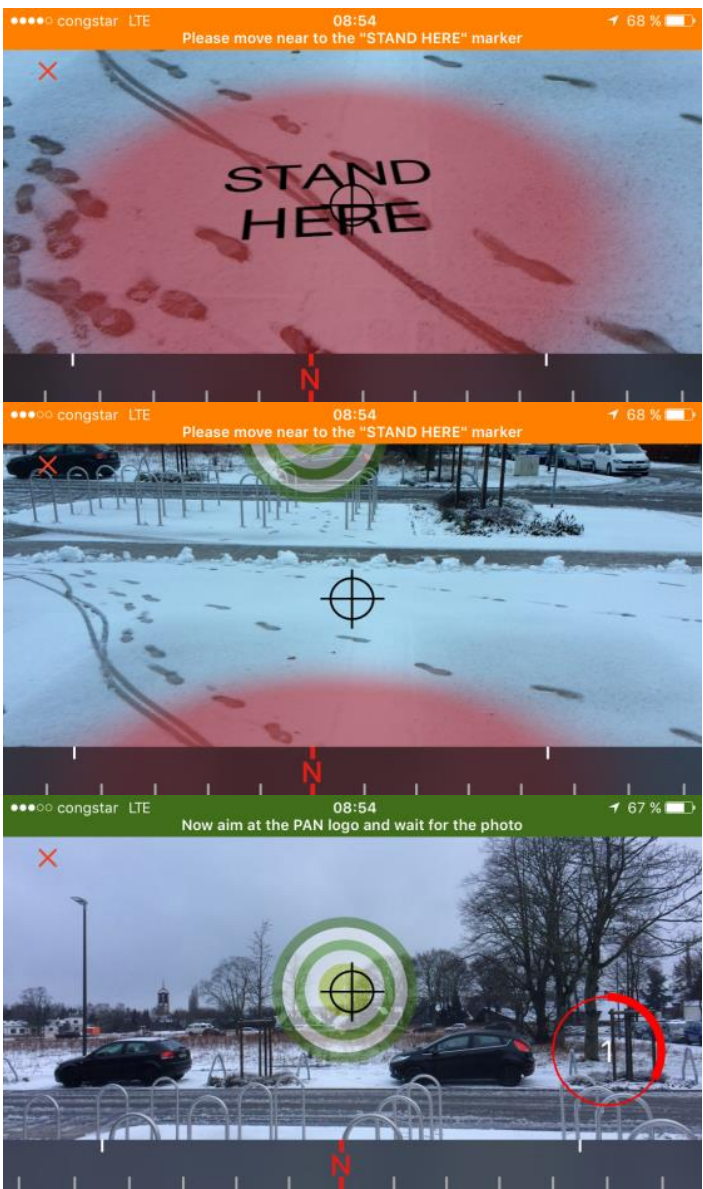

Figure 3. Augmented guiding to the virtual photo location (a), target (b) and automatic photo triggering (c). 
For this project the AR frameworks DroidAR (Android) and TGLAugmentedRealityView (iOS) have been used and strongly adapted. This leads to problems and limitations as both frameworks only cover basic AR functionalities and both operating systems are very diverse in terms of programming language, system architecture and sensor APIs. A crossplatform software development kit (SDK) would have been easier to handle but is also often associated with high license costs. We expect an increased accuracy and viability with a switchover to a more comprehensive and specialised SDK in future versions (e.g. with the Wikitude SDK).

\subsection{Post processing}

Post processing steps are needed for several reasons and is currently carried out on the server. The first reason is to avoid so called digital vandalism. The $\mathrm{AR}$ view is not yet able to detect if anything is between the target and the camera. This can lead to unintended images of faces or people in general. This can of course happen intentionally or accidentally. Several computer vision frameworks are capable of detecting human faces or computing similarities between two images. In this case OpenCV is used to mark photos to be supervised by an operator. Human interaction is still needed because these problems are still ongoing research in computer vision and not all photos can be automatically used.

The second processing step is to compute time-lapse videos from a series of images. If enough photos are taken these timelapse videos are used as a visualization of visible changes over time. As the time-period of different photos for each location is still small only phenological changes are visible. The time-lapse computation is currently a semi-automatic approach. Small changes in perspective can be eliminated with the Hugin software. To reach at least 30 frames per second transition frames are computed with Butterflow and are then combined to a video with FFMpeg.

\section{RESULTS}

The current workflow is tested in cooperation with the UNESCO Global Geopark TERRA.vita in Germany. Two specific sites are used as experimental locations for the app. One of the test sites is an abandoned limestone quarry in the Teutoburg Forest near Lengerich, where many animal and plant species find optimal life conditions. First results from this test site can be seen in Figure 4).

\subsection{Environmental education}

One aim of the project was to test how new technology (like AR) could be used to educate people and to use the apps as an touristic marketing instrument for UNESCO Geoparks. Therefore, each location is provided with additional information and graphics about its important properties and its influence on the surrounding environment (see Figure 5). The app can also be used in conjunction with already existing audio commentary for specific locations in the Geopark TERRA.vita. Efforts are being made to implement direct communications channels to specialists or scientists. By this users will be able to ask questions about their current location or to give feedback to increase the citizen science aspect. By this users are being made aware why their contribution is useful and how it is used (Adriaens et al., 2015). (a)

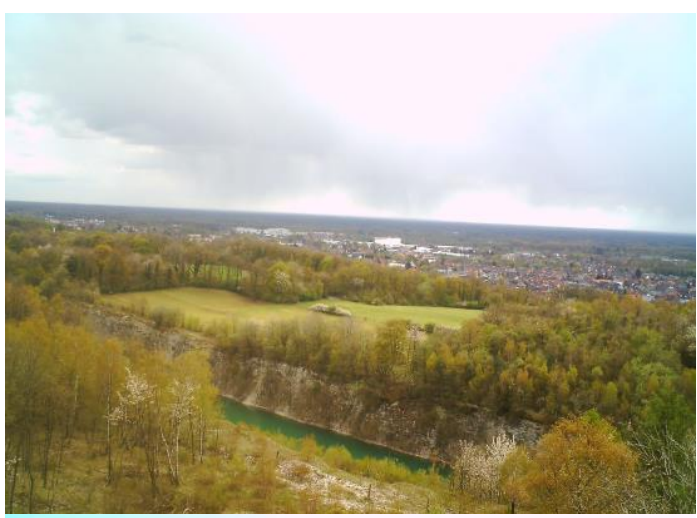

(b)

(c)

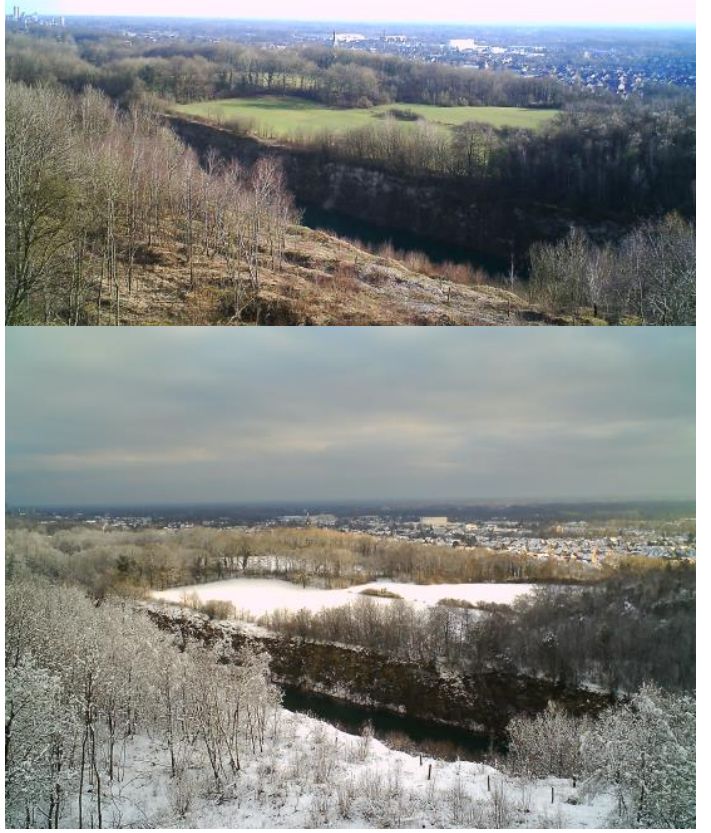

Figure 4. Resulting photographs at three various points of time,

(a) summer, (b) fall and (c) winter at the Lengerich Canyon.
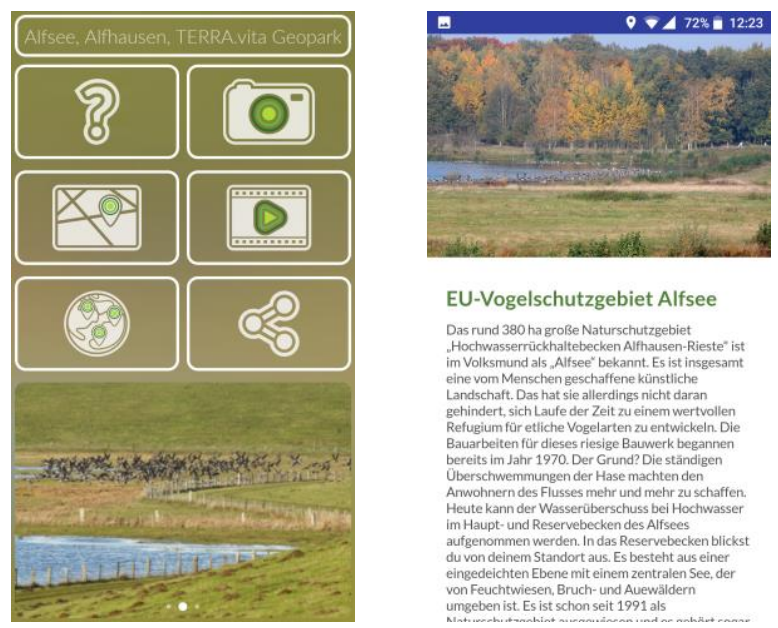

EU-Vogelschutzgebiet Alfsee

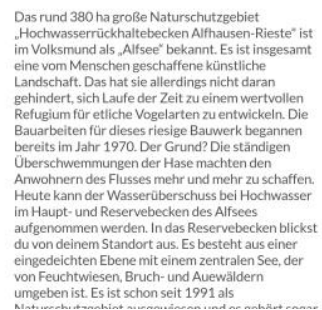

Figure 5. App main menu (left) and educational information text and graphics for the POI. 
A further approach is to use the app for guided tours by experts and to expand the audio-visual material for more locations. First tests showed that the app can also be used for groups of children or students as a Geocaching game to find interesting sites in the Geopark. The gamification approach allows the Geopark to expand its influence area to a much wider audience (Adriaens et al., 2015)

\section{DISCUSSION}

Ongoing documentation over long periods of time is an important aspect for nature preservation for coming generations if environmental phenomena like climate change or erosion irretrievably change geoobjects. This project shows how these changes can be monitored and documented with modern technologies and how to make the results accessible for the general public or scientists.

The project combines in exemplary manner environmental documentation (or monitoring) with environmental education. By using the presented app the users get in direct contact with geotopes in the UNESCO Geopark TERRA.vita and are drawn to attention to their value, beauty and significance. Therefore this approach is also used as a general marketing instrument to spread the basic concerns of Geoparks or other nature conservation areas. Particularly younger people are attracted to smartphones and new technology in general but are more reserved about environmental concerns or sustainability. The approach offers contributions to environmentally sound tourism and environmental education.

Furthermore, users become scientists indirectly by utilising the citizen science and crowdsourcing approach. By taking a photo they contribute to a necessary long time monitoring of protected areas. The collection and evaluation of the images by trained specialists of the Geoparks enable a targeted geotope management. Usually all Geoparks have to establish an ecological development plan to protect and sustain the environment and document corresponding changes. UNESCO Geoparks are revalidated every four years and this project can help to document how the plans for and conditions of the geotopes and geosites have developed.

\section{ACKNOWLEDGEMENTS}

This work is sponsored by Deutsche Bundesstiftung Umwelt (DBU).

\section{REFERENCES}

Adriaens, T., Sutton-Croft, M., Owen, K., Brosens, D., Valkenburg, J. van, Kilbey, D., Groom, Q., Ehmig, C., Thürkow, F., Hende, P. Van, Schneider, K., 2015. Trying to engage the crowd in recording invasive alien species in Europe: experiences from two smartphone applications in northwest Europe. Management of Biological Invasions, 6, 2, pp. 215225 .

Goodchild, M. F., 2007. Citizens as Voluntary Sensors: Spatial Data Infrastructure in the World of Web 2.0. International Journal of Spatial Data Infrastructures Research, 2, 24-32, doi:10.1016/j.jenvrad.2011.12.005.

Hadjiprocopis, A., Ioannides, M., Wenzel, K., Rothermel, M., Johnsons, P.S., Fritsch, D., Doulamis, A., Protopapadakis, E., Kyriakaki, G., Makantasis, K., Weinlinger, G., Klein, M., Fellner, D., Stork, A., Santos, P., 2014. 4D reconstruction of the past: the image retrieval and 3D model construction pipeline, in: Hadjimitsis, D.G., Themistocleous, K., Michaelides, S., Papadavid, G. (Eds.), Second International Conference on Remote Sensing and Geoinformation of the Environment (RSCy2014). p. 922916. doi:10.1117/12.2065950.

Ielenicz, M, 2009. Geotope, geosite, geomorphosite. The Annals of Valahia University of Târgovişte, Geographical Series 9, 7-22.

Kamarainen, A. M., Metcalf, S., Grotzer, T., Browne, A., Mazzuca, D., Tutwiler, M. S., Dede, C., 2013. EcoMOBILE: Integrating augmented reality and probeware with environmental education field trips. Computers \& Education, 68 (2013), 545-556, doi:10.1016/j.compedu.2013.02.018.

Silvertown, J., 2009. A new dawn for citizen science. Trends in

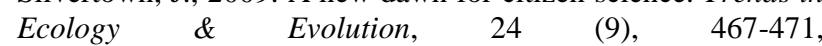
doi:10.1016/j.tree.2009.03.017.

Veas, E., Grasset, R., Ferencik, I., Grünewald, T., Schmalstieg, D., 2013. Mobile augmented reality for environmental monitoring. Personal and Ubiquitous Computing, 17, 7, pp. 1515-1531, doi:10.1007/s00779-012-0597-z.

West, R., Halley, A., O’Neil-Dunne, J., Gordon, D. and Pless, R., 2013. Collaborative Imaging of Urban Forest Dynamics: Augmenting Rephotography to Visualize Changes over Time. Proc. SPIE 8649, The Engineering Reality of Virtual Reality 2013, 86490L (March 4, 2013), doi:10.1117/12.2008109. 